\title{
Каналы дислокаций на поверхности кристаллов (по данным АСМ)
}

\section{Пискунова Н.Н.}

Институт геологии Коми НЦ УрО РАН, Сыктыєккар, piskunova@geo.komisc.ru

Аннотация. В статье представлены результаты исследования с помощью in-situ атомно-силовой микроскопии (ACM) дислокационных спиралей и наноразмерных выходов полых каналов. Показано как форма канала сложной дислокации зависит от расположения выходов слагающих ее одиночных дислокаций. Получены ex-situ изображения дислокационных каналов и холмиков роста на внутренних стенках включений кристаллов горного хрусталя (м. Желанное, Приполярный Урал, Россия) и фенакита (Изумрудные копи, Средний Урал, Россия). Доказано, что дислокационные каналы, а также их скопления не могут быть причиной утечки растворов из флюидных включений в природе и в ходе термобарогеохимических исследований.

Ключевые слова: атомно-силовая микроскопия, рост кристаллов, дислокационный холмик, выходы каналов дислокаций, кварц, фенакит, флюидные включения.

\section{Dislocation channels on the crystal surface (according to AFM data)}

\author{
Piskunova N.N. \\ Institute of Geology of the Komi SC UrD RAS, Syktyvkar, Russia, piskunova@geo.komisc.ru
}

\begin{abstract}
Presented here are the results of our in situ atomic-force microscopy (AFM) investigations of the dislocation spirals and spouts of its hollow channels at the nanoscale. We show how the form of a complex dislocation channel depends on the interposition of the single dislocation channels. The ex-situ images of the spouts of dislocation channels and dislocation growth hillocks on the inner walls of inclusions of rock crystal crystals (M. Zhelannoe, Subpolar Urals, Russia) and phenakite (Emerald mines, Middle Urals, Russia) have been obtained. It has been proven that dislocation channels, as well as their accumulations, cannot be the cause of the extrusion of the solution through dislocation's channels both in nature and during thermobarogeochemical studies.
\end{abstract}

Key words: atomic-force microscopy, crystal growth, dislocation hillock, dislocation channel spouts, quartz, phenakite, fluid inclusions.

\section{Введение}

Дислокационные холмики на поверхности природных и синтетических кристаллов являются основными источниками ступеней, за счет которых растет кристаллическая поверхность и которые позволяют кристаллу расти даже в условиях весьма низких значений пересыщения. В работе (Cabrera, Levine, 1956) впервые теоретически показано, что дислокация в кристалле должна иметь полое ядро, и возможно, выход канала на кристаллическую поверхность тоже может быть в виде отверстия. Вскоре после этого появились экспериментальные наблюдения полых каналов, венчающих дислокационные холмики на кристаллах (Amelinckx, Strumane 1959; Sunagawa, Bennema, 1981; Bennema, 1983). Введение в 1990-х годах в практику ростовых наблюдений атомно-силовой микроскопии (АСМ) позволило исследователям получить изображения дислокационных каналов на поверхности в масштабах элементарной ячейки, в том числе непосредственно в растворе (Yoreo et al., 1997, Heydemann et al., 1998; Kuznetsov et al., 1999; Н. Рашкович, 2001). Сканирование в АСМ происходит заостренной иглой, что позволяет сделать профильный разрез рельефа и доказать, что канал действительно полый, а не является результатом искусственного изменения контрастности. Несмотря на такие возможности, исследования в этой области по некоторым причинам не теряют своей актуальности. Во-первых, круг кристаллов для таких наблюдений ограничивается органическими веществами, которые имеют крупные строительные единицы. Кроме того, растворы должны быть полностью прозрачными, ведь через них проходит лазерный луч, отклонения которого считываются в процессе сканирования. Важной причиной является также малая изученность поверхности природных кристаллов с точки зрения наноразмерных ростовых процессов. В настоящей ра- 
боте приведены результаты исследования с помощью АСМ наноразмерных морфологических особенностей рельефа в области выхода дислокационных каналов на поверхность кристаллов различного происхождения.

\section{Методика исследования}

Исследования проводились на оборудовании ЦКП «Геонаука» (Сыктывкар), использовался атомно-силовой микроскоп Ntegra Prima (NT-MDT, Россия) и стандартные кремниевые кантилеверы (NanoProbe, Великобритания) с радиусом закругления кончика 5 нм. Модельные кристаллы диоксидина (гидроксиметихиноксалиндиоксида $\mathrm{C}_{10} \mathrm{H}_{10} \mathrm{~N}_{2} \mathrm{O}_{4}$ ) для in-situ наблюдения процессов роста и растворения выращивались непосредственно в жидкостной ячейке микроскопа. Диоксидин кристаллизуется в моноклинной сингонии, образуя в основном таблитчатые кристаллы. Съемки проводились в режимах прерывистого и полного контакта острия с поверхностью. К полученным изображениям применялись стандартные методы их обработки, включая профильные разрезы.

Часть ex-situ изображений получена на внутренних стенках флюидных включений в природных кварце (месторождение Желанное, Приполярный Урал, Россия) и фенаките (Изумрудные копи, Средний Урал, Россия). После вырезания из кристалла пластинки пришлифовывались, образцы выдерживались в ультразвуковой ванне для очистки от солей и обломков. После пришлифовки внутренние стенки частично вскрытых флюидных включений были изучены с помощью АСМ.

\section{Результаты и их обсуждение}

Получены последовательные изображения растворения и роста на грани (100) кристалла диоксидина на дислокационных спиралях различных типов. Установлено, что рост и растворение на винтовых дислокациях на данной грани происходит в основном за счет распространения элементарных ростовых слоев. Высота их составляет 8.8 ангстрем, что равно параметру $а$ элементарной ячейки, и равно одному их размеров молекулы $\mathrm{C}_{10} \mathrm{H}_{10} \mathrm{~N}_{2} \mathrm{O}_{4}$. Известно, что диаметр канала дислокационного источника пропорционален квадрату числа испускаемых источником ступеней (Yoreo et al., 1997). Это определяет тот факт, что диаметр канала источника на диоксидине, образованного одной или двумя ступенями, составляет первые десятки нанометров. Такие каналы имеют форму ровного круга. Так как полые дислокационные каналы образуются из-за того, что ступень вынуждена «обходить» точку выхода на поверхность кристалла винтовой дислокации, то форма каналов на сложных источниках зависит от взаимного расположения выходов одиночных дислокаций одного знака. При этом могут образовываться выходы каналов самых причудливых форм (рис. 1).

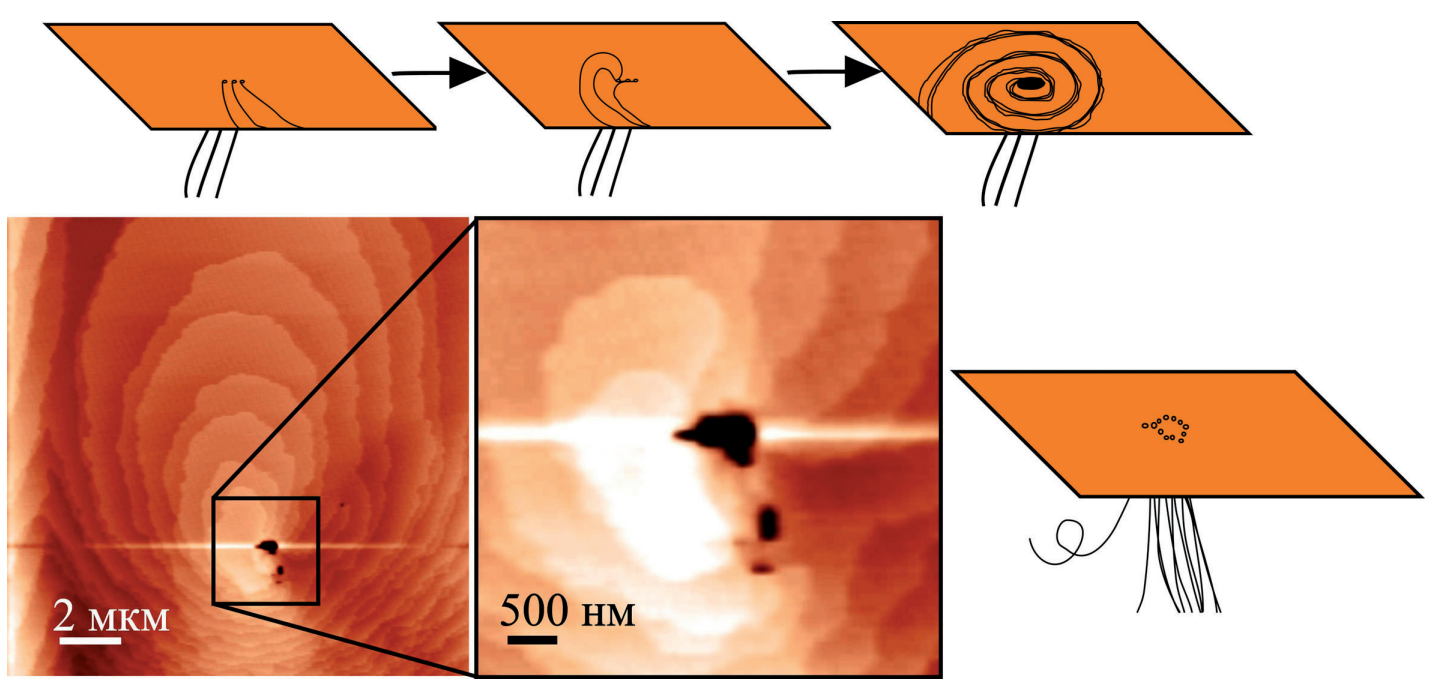

Рис. 1. АСМ-изображение полого канала на вершине сложного дислокационного источника. Показан механизм, по которому происходит объединение выходов нескольких дислокаций одного знака в один канал.

Fig. 1. AFM image of a surface of a model crystal, showing a spout of hollow core a complex dislocation source. It shows the mechanism for combining the spouts of several dislocations of the same sign. 


\section{Каналы на поверхности природных кристаллов}

Изучение граней природных кристаллов с помощью сканирующей зондовой микроскопии сопряжены с множеством трудностей и нешироко представлены в литературе. Недостаток питания на финальном этапе приводит к неравномерности снабжения поверхности строительными единицами, еще большему укрупнению выдающихся акцессориев роста и отставанию от них гладких участков. Кроме этого, на природных кристаллах часто имеется механические потертости, растворенные участки, а также пленки гетерогенных примесей, все это делает природные грани малоинформативными для изучения в наноразмерном масштабе. Нами получены некоторые свидетельства послойного дислокационного роста на природных кристаллах. Полые каналы наноразмерной ширины на вершинах холмиков в таких исследованиях встречаются крайне редко. Большей частью на АСМ-изображениях фиксируется результат частичного растворения поверхности в области канала. Поэтому диаметр канала простой дислокации, испускающей одиночную ступень, может оказаться микрометровым.
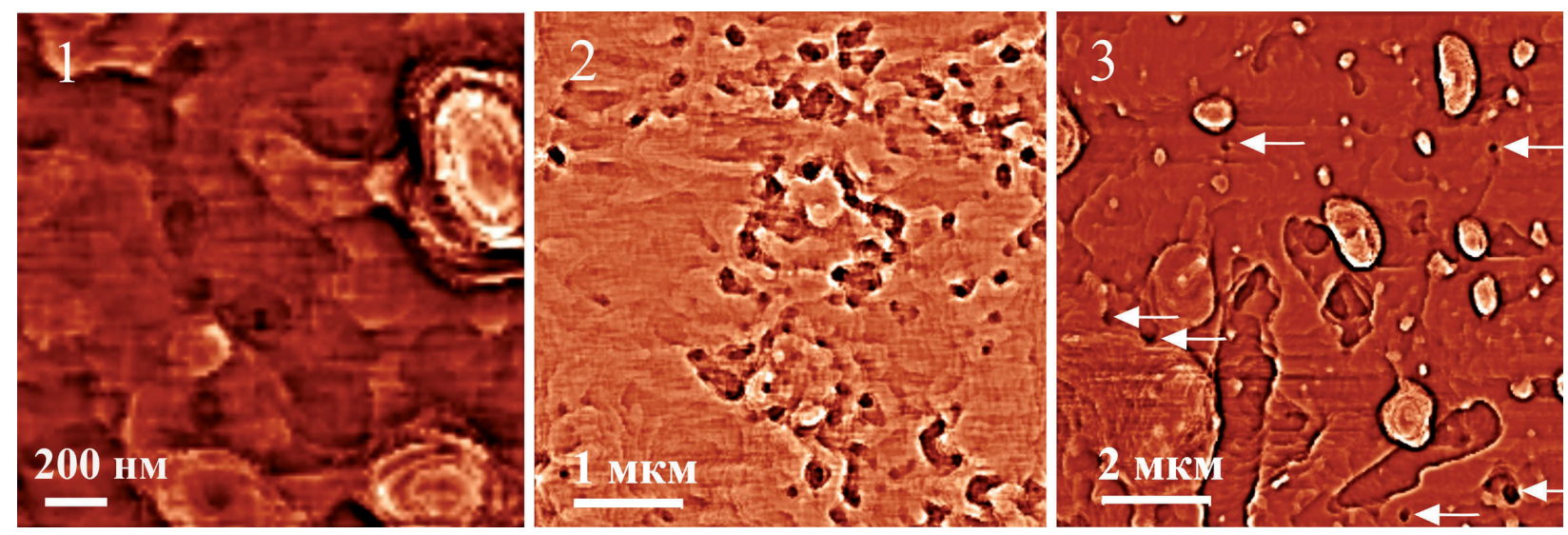

Рис. 2. 1- холмик, выросший на внутренней стенке флюидного включения в кварце, в центре которого виден полый канал маленького диаметра; 2 - участок включения в кварце, содержащий большое скопление дислокационных выходов; 3 - внутренняя поверхность включения в фенаките, с холмиками и выходами каналов (показаны стрелками).

Fig. 2. 1 - growth hillocks on the inner surfaces of fluid inclusions in a quartz crystal, with the hollow channel of small diameter in the center; 2 - area of the fluid inclusion in a quartz with the multiple dislocation spouts; 3 - growth hillocks and hollow channels on the inner surfaces of fluid inclusions in a phenakite crystal (shown by arrows).

Предполагая, что акцессории роста на стенках флюидных включений внутри кристаллов могли сохранить тонкую структуру своей поверхности, мы провели изучение полувскрытых включений в нескольких кристаллах кварца и фенакита (рис. 2). Обнаруженные нами на этих поверхностях холмики являются классическими дислокационными холмиками роста, нарастающими по известному механизму Франка, они имеют спиральное строение и полый канал на вершине (рис. 2.1). Данные холмики выросли из вещества законсервированного внутри флюидных включений.

Кроме этого, на отдельных участках стенок флюидных включений в горном хрустале и фенаките обнаружены фигуры глубокого черного цвета размером от 50 до 250 нм, которые также представляют собой выходы дислокаций (рис. 2.2). Вещество из раствора внутри включений откладывалось не только на холмики, но и на торцы имевшихся ступеней, на пути которых были полые каналы. Из-за энергетических причин, ступень не может подойти к самому краю глубокого отверстия, останавливаясь раньше. В результате дальнейшего флуктуирования (наступания-отступания) ступени происходит огибание канала-препятствия, иногда объединение пойм нескольких соседних каналов, что визуально увеличивает диаметр канала. В области канала дислокация характеризуется лишней энергией, которая суммируется из энергии оборванных либо искаженных связей в ядре дислокации и энергии упругих напряжений вокруг дислокаций, поэтому он сам редко зарастает при росте. 
Причин формирования флюидных включений в природе может быть множество (Плечов, 2014), среди основных исследователи называют локальное уменьшение или увеличение величины пересыщения и возникновения из-за этого градиента концентрации перед фронтом роста. При этом происходит искривление торцов кинематических волн и истинных макроступеней, на них образуются зубцы и нависание, затем смыкание грота с захватом включения (Чернов, 1987). Результаты наших in-situ исследований позволяют утверждать, что такое большое скопление дислокационных выходов как на рисунке 2.2, могло само вызвать появление изученного нами флюидного включения. Нами показано, что если перед фронтом роста макроступени в качестве препятствия оказывается выход даже единичной дислокации, это всегда вызывает торможение макроступени (Пискунова, 2012). Таким образом, в месте выхода нескольких близкорасположенных каналов с большой вероятностью возникает объемный дефект.

\section{Вытекание раствора флюидных включений через каналы}

При диаметре 50-250 нм, дислокационные каналы в кварце бывают очень протяженными - десятки и больше миллиметров. Может ли раствор, находящийся внутри флюидного включения продавливаться (Hall, Sterner, 1993; Bakker, Jansen, 1994) через такие каналы? В частности, происходит ли незаметное вытекание раствора в тонкой пластинке при термобарогеохимических исследованиях, приводя тем самым к снижению давления и повышению температуры гомогенизации?

Используя формулу Хагена-Пуазейля (капиллярная модель протекания), получим количество жидкости $Q$, протекающей через капилляр диаметра $d$ в ед. времени:

$$
Q=\frac{\pi \Delta p d^{4}}{16 \eta \Delta L}
$$

где $\Delta p$ - разность давлений на концах капилляра (Па), $L$ - длина капилляра, $\eta$ - вязкость $\left(2 \cdot 10^{3}\right.$ Па $\left.\cdot \mathbf{c}\right)$. Таким образом, что для того, чтобы через капилляр длиной $5 \cdot 10^{-4}$ м и диаметром 100 нм вытекло несколько миллилитров жидкости, необходимо приложить давление, на тридцать порядков выше атмосферного. Данная формула не учитывает то, какое значение приобретает сила поверхностного натяжения в наноразмерных масштабах. Мнения исследователей (Сдобняков, Самсонов, 2003) по этому вопросу расходятся, однако в случае флюидных включений можно предположить, что наноразмерные эффекты поверхностного натяжения еще более затрудняют вытекание растворов из включений.

Если имеется не единичный канал, а скопление каналов, то по фрактальной модели (Тихомиров и др., 2011), в основе которой лежит уравнение Пуазейля, переход от состояния герметичности к протеканию наступает при превышении порогового значения концентрации пор, равного отношению объема пор к объему образца с порами. АСМ дает очень высокую точность подобных расчетов, так для участка поверхности, отмеченного стрелкой на рисунке 7 с большим количеством видимых пор, значение концентрации составляет всего 0.1727, что минимум в два раза меньше порогового, рассчитанного в работе (Тихомиров и др., 2011). Необходимо отметить, что описанная модель оценивает протекание (просачивание) через пористые материалы как через соединение инженерных поверхностей, но также не учитывает наноразмерные эффекты поверхностного натяжения. Таким образом, мы считаем, что дислокационные каналы, в том числе их массовые скопления не могут быть причиной утечки растворов из флюидных включений в природе и в ходе термобарогеохимических исследований. Этот вывод согласуется с результатами экспериментов в работе (Смирнов и др., 2011), авторы которой считают основными причинами утечки растворов наличие трехмерных дефектов кристаллической структуры, таких как открытые и залеченные трещины.

\section{Заключение}

По данным АСМ установлено, что одним из основных факторов, влияющих на формирование реальной картины строения и эволюции поверхности на наноуровне, являются особенности рельефа дислокационных холмиков, их взаимодействие друг с другом и со ступенями. Визуализированы наноразмерные выходы полых каналов на вершинах холмиков, показано как форма выхода канала 
сложной дислокации зависит от расположения каналов слагающих ее одиночных дислокаций. Получены ex-situ изображения выходов дислокационных каналов и дислокационных холмиков роста на внутренних стенках включений кристаллов горного хрусталя (м. Желанное, Приполярный Урал, Россия) и фенакита (Изумрудные копи, Средний Урал, Россия). Доказано, что дислокационные каналы, а также их скопления не могут быть причиной утечки растворов из флюидных включений в природе и при термобарогеохимических исследованиях. Установлено, что, скопления выходов дислокационных каналов, обнаруженные на АСМ-изображениях стенок флюидных включений, могут являться главной причиной появления самих этих включений.

Работа выполнена при частичной финансовой поддержке РФФИ (19-05-00460) и Программы фундаментальных научных исследований УрО РАН № 18-5-5-44.

\section{Литература}

1. Cabrera N., Levine M.M. On the dislocation theory of evaporation of crystals // Phil. Mag. 1956. V. 1. P. 450.

2. Amelinckx S., Strumane G. A growth or dissolution mechanism. Hollow cores will High Temperature Semiconductor / In: Silicon Carbide. A. Boston. 1959. P. 162.

3. Sunagawa, I., Bennema, P. Observations of the influence of stress fields on the shape of growth and dissolution spirals // J. of Cryst. Growth. 1981. V. 53. P. 490-504.

4. Bennema P. Science of Crystal Growth: Rough or Flat Surfaces; Formation and Movement of Steps in Relation to Surface Mobilities and Defects / In: Surface Mobilities on Solid Materials. Fundamental Concepts and Applications. Ed. Vu Thien Binh. Springer. Boston. MA. 1983. P. 275-340.

5. De Yoreo J.J., Land T.A., Lee J.D. Limits on surface vicinality and growth rate due to hollow dislocation cores on KDP $\{101\}$ // Physical Review Letters. 1997. V. 78(23). P. 4462-4465.

6. V.D. Heydemann, E.K. Sanchez, G.S. Rohrer, M. Skowronski. The structural evolution of Lely seeds during the initial stages of sic sublimation growth // Mat. Res. Soc. Symp. Proc. 1998. V. 483. P. 295-298.

7. Kuznetsov Y.G., Malkin A.J., Mcpherson A. AFM studies of the nucleation and growth mechanisms of macromolecular crystals // Journal of Crystal Growth. 1999. V. 196(2-4). P. 489-502.

8. Рашкович Л.Н. Атомно-силовая микроскопия процессов роста кристаллов в растворе // Соросовский образовательный журнал. 2001. Т. 7. № 10. С. 102-108.

9. Плечов П.Ю. Методы изучения флюидных и расплавных включений. Москва. Изд-во: «КДУ». 2014. 268 с.

10. Чернов А. А. Элементарные процессы роста кристаллов из растворов // УФН. 1987. № 153. С. 678-681.

11. Пискунова Н.Н. Роль дефектов в процессах роста и растворения кристаллов (по данным атомно-силовой микроскопии) // Научные основы синтеза минералов и новых материалов (под ред. академика А.M. Асхабова). Сыктывкар. Изд-во: Геопринт. 2012. С. 89-104.

12. Hall D.L., Sterner S.M. Preferential water loss from synthetic fluid inclusions // Contr. Miner. Petrol. 1993. V. 114. P. 489-500.

13. Bakker R.J., Jansen J. B.H. A mechanism for preferential $\mathrm{H} 2 \mathrm{O}$ leakage from fluid inclusions in quartz, based on TEM observations // Contributions to Mineralogy and Petrology. 1994. V. 116 (1-2). P. 7-20.

14. Сдобняков Н.Ю., Самсонов В.М. Исследование размерной зависимости поверхностного натяжения твердых наночастиц на основе термодинамической теории возмущений. // Известия ВУЗов: Химия и химическая технология. 2003. № 46 (5). С. 90-94.

15. Тихомиров В.П., Горленко О.А., Измеров М.А. Протекание через фрактальную пористую среду // Известия Самарского научного центра Российской академии наук. 2011. № 13 (4). С. 879-883.

16. Смирнов С.З., Томас В.Г., Соколова Е.Н., Куприянов И.Н. Экспериментальное исследование герметичности включений водосодержащих силикатных расплавов при внешнем давлении $\mathrm{D}_{2} \mathrm{O}$ при $650{ }^{\circ} \mathrm{C}$ и 3 кбар // Геология и геофизика. 2011. № 52 (5). С. 690-703. 